\title{
DESEMPENHO DE UMA ADUBADORA DESENVOLVIDA PARA INCORPORAÇÃO DE COMPOSTO ORGÂNICO EM SISTEMA DE SEMEADURA DIRETA DE MILHO
}

Luiz Fernando Favarato ${ }^{1}$, João Carlos Cardoso Galvão², Caetano Marciano de Souza ${ }^{3}$, Haroldo Carlos Fernandes ${ }^{4}$, Darlan Nascentes Cunha ${ }^{5}$

\section{RESUMO}

Neste trabalho, objetivou-se avaliar o desempenho de uma adubadora desenvolvida para incorporação de composto orgânico em sistema de semeadura direta de milho, quantificando a força de tração requerida, a potência demandada, o consumo horário e operacional de óleo diesel, a capacidade de trabalho, a incorporação do composto orgânico no solo e o índice de velocidade de emergência das plântulas de milho. As variáveis, força de tração requerida, consumo de combustível, capacidade de trabalho teórico e consumo operacional de combustível foram utilizadas para avaliar o desempenho do conjunto trator-adubadora, além da profundidade de incorporação do composto orgânico e índice de velocidade de emergência das plântulas de milho. A adubadora poderá ser traciona/acionada por tratores de baixa potência, menor que 40 cv. A adubadora apresenta baixa capacidade de trabalho e elevado consumo operacional de óleo diesel. O conjunto trator-adubadora foi eficiente em incorporar o composto orgânico no solo na camada de 0-4 cm de profundidade. A incorporação do composto orgânico propiciou incremento de 36 \% no índice de velocidade de emergência de plântulas de milho no solo sem palhada de milheto.

Palavras-chave: volatilização, cultivo orgânico, potência, Zea mays L

\section{ABSTRACT \\ PERFORMANCE OF A FERTILIZER SPREADER DESIGNED TO INCORPORATE OF ORGANIC COMPOST IN DIRECT SEEDING SYSTEM OF MAIZE}

This study was done to evaluate the performance of a fertilizer spreader designed to incorporate organic compost in direct-seeding system of maize, by quantifying traction force requirement, hourly and operational fuel consumption, power demand, working capacity, compost incorporation in soil and the maize seedling emergence speed index. Traction force requirement, fuel consumption and working capacity were used to evaluate the performance besides compost incorporation depth and seedling emergence speed index. The fertilizer spreader can be used by low power $(>40 \mathrm{cv})$ tractors. The fertilizer spreader showed low working capacity and high operating fuel consumption. The designed was effective for incorporating compost into soil to a depth of up to $0.04 \mathrm{~m}$. The incorporation of compost increased seedling emergence speed index by $36 \%$ in soil without millet chaff.

Keywords: volatilization, organic cultivation, power, Zea mays L

\footnotetext{
Recebido para publicação em 24/05/2012. Aprovado em 01/08/2012.

1- Engenheiro Agrônomo, Estudante de doutorado da UFV/Viçosa-MG, lfavarato@yahoo.com.br

2- Engenheiro Agrônomo, Professor Associado III, Departamento de Fitotecnia, UFV/Viçosa-MG, jgalvao@ufv.br

3- Engenheiro Agrônomo, Professor Associado III, Departamento de Fitotecnia, UFV/Viçosa-MG, cmsouza@ufv.br

4- Engenheiro Agrícola, Professor. Adjunto, D.S., Departamento de Engenharia Agrícola, UFV/Viçosa-MG, haroldo@ufv.br

5- Estudante de agronomia, UFV/Viçosa-MG, darlannc@yahoo.com.br
} 


\section{INTRODUÇÃO}

O sistema de plantio direto orgânico integra o benefício da conservação do solo do plantio direto com a produção orgânica de alimentos. A aplicação do composto orgânico nesse sistema é feita na superfície do solo, o que possivelmente diminui a absorção de nutrientes pelas raízes e acarreta perdas de nitrogênio por volatilização de $\mathrm{NH}_{3}$. A perda por volatilização de $\mathrm{NH}_{3}$ do nitrogênio lábil da decomposição do adubo orgânico pode diminuir seu benefício à cultura principal (JANZEN \& MEGINN,1991).

Dessa forma, a incorporação mecânica do adubo orgânico, somente na linha de plantio, através de enxadas rotativas, consiste em um meio de minimizar o problema da volatilização do $\mathrm{NH}_{3}$, além de maximizar os efeitos físicos, químicos e biológicos do mesmo, sem fugir a concepção do sistema de plantio direto.

No entanto, os cultivos no sistema de plantio direto orgânico são feitos com as máquinas utilizadas no sistema de plantio direto tradicional como semeadoras-adubadoras que possuem sistemas de distribuição e incorporação para adubos químicos. Isso acontece porque no mercado de máquinas não se encontra uma semeadora-adubadora que faça a distribuição e incorporação do adubo orgânico e semeadura simultaneamente.

$\mathrm{O}$ não desenvolvimento de projetos de máquinas para tal fim, por parte das grandes empresas, se dá pela pouca demanda do mercado de máquinas específicas para o plantio direto orgânico, pois este novo sistema de cultivo ainda é pouco divulgado, com poucos agricultores que o praticam, necessitando ainda de estudos para ser aperfeiçoado.

As necessidades de tração dos implementos agrícolas são dependentes de variáveis como o solo, o próprio implemento e outras. Dentro da variável solo, destacam-se: a distribuição do tamanho dos agregados; a textura; o teor de água; a densidade do solo; a estrutura e os efeitos da declividade, da vegetação e dos resíduos de culturas anteriores. $\mathrm{O}$ implemento pode influir no esforço de tração, conforme o tipo de ferramenta usada, as características do metal que está em contato com o solo, a superfície em contato com o solo, a curvatura, a forma e as condições da superfície da ferramenta onde a força é aplicada. Outras variáveis incluem largura e profundidade do sulco e velocidade de deslocamento da máquina (MODOLO et al., 2004).

Avaliar o desempenho de protótipos é uma ferramenta indispensável à indústria de máquinas agrícolas. Nesse momento do ciclo de vida do produto, é interessante a interação entre instituições de pesquisa e indústria. As principais saídas de tal círculo virtuoso são a melhoria dos equipamentos, com o retorno oferecido à indústria pela instituição de pesquisa, na forma de relatórios técnicocientíficos, a melhoria das práticas agrícolas que envolvem máquinas e mecanização em benefício dos agricultores, e aumento da produção científica do país de uma maneira sólida, com ênfase na realidade das empresas e dos produtores rurais (DIAS, 2009).

O objetivo do trabalho foi avaliar o desempenho de uma adubadora desenvolvida para incorporação de composto orgânico em sistema de semeadura direta de milho, quantificando a força de tração requerida, a potência demandada, o consumo horário e operacional de óleo diesel, a capacidade de trabalho, a incorporação do composto orgânico no solo e o índice de velocidade de emergência das plântulas de milho.

\section{MATERIAL E MÉTODOS}

O trabalho foi realizado na Estação Experimental de Coimbra pertencente à Universidade Federal de Viçosa, na cidade de Coimbra, MG, no mês de Fevereiro de 2011. A área caracteriza-se, climaticamente, por temperatura média anual de $19^{\circ} \mathrm{C}$ e precipitação média anual de 1.300 a 1.400 $\mathrm{mm}$, concentrada, principalmente, durante o período de outubro a março, com média anual de umidade relativa do ar de 80 a $85 \%$ e temperatura média, neste período, de $23^{\circ} \mathrm{C}$.

Os testes foram realizados em um Argissolo Vermelho-Amarelo, fase terraço, segundo EMBRAPA (2006), classe de solo muito utilizada na região para a cultura do milho. O solo é classificado por textura muito argilosa (770 $\mathrm{g} \mathrm{kg}^{-1}$ de argila), apresentando densidade média de $1,05 \mathrm{~g} \mathrm{dm}^{-3}$. O teor de água no solo situava-se na faixa considerada friável para este solo, recomendada para operações de semeadura.

A adubadora utilizada foi desenvolvida e 
montada no Laboratório de Máquinas Agrícolas do Departamento de Engenharia Agrícola, utilizando o chassi de uma semeadora-adubadora FNIHOWARD Rotacaster, modelo RT 6010. A máquina possui duas linhas de distribuição de composto orgânico espaçadas de $0,80 \mathrm{~m}$ e trabalha montada no sistema de engate de três pontos e apresenta mecanismo de abertura do sulco acionado pela tomada de potência.

Para determinação da demanda de potência foram utilizados dois tratores com potência nominal do motor de $80 \mathrm{cv}$, um Agrale modelo 5080.4 Turbo $4 \times 2$ TDA (tração dianteira auxiliar) para acionar a adubadora e um Valtra modelo 800 4×2 TDA para tracionar o conjunto trator-adubadora. A avaliação foi realizada em duas etapas, a primeira avaliou-se com a adubadora acoplada e a segunda etapa sem a adubadora acoplada.

A resistência ao rolamento do trator Agrale, utilizado para acionar a adubadora por meio da tomada de potência foi descontada no momento em que foi feito o teste sem a adubadora acoplada. A patinagem do trator foi de 7,05\%.

As variáveis, força de tração requerida, consumo horário e operacional de óleo diesel e capacidade de trabalho teórico foram utilizadas para avaliar o desempenho do conjunto trator-adubadora.

Para a determinação da força de tração utilizouse uma célula de carga marca KRATOS, com capacidade de $50 \mathrm{kN}$ e fator de correção 583,64. Determinou-se a leitura média da célula de carga e o tempo gasto para percorrer uma distância de 20 $\mathrm{m}$. Com estes dados, foram calculadas a força de tração requerida e a velocidade de deslocamento. Através dos valores de força de tração e velocidade de deslocamento, foi obtida a potência demandada utilizando a equação (1):

$$
P=\frac{F x V}{1000}
$$

em que

$\mathrm{P}=$ Potência $(\mathrm{kW})$;

$\mathrm{F}=$ Força de tração $(\mathrm{N})$; e

$\mathrm{V}=$ Velocidade de deslocamento $\left(\mathrm{m} \mathrm{s}^{-1}\right)$.

O consumo horário de combustível foi determinado utilizando-se uma proveta graduada em mililitros, acoplada ao sistema de alimentação de combustível do trator Valtra, usado para tracionar e acionar a adubadora. A rotação do motor durante o teste foi correspondente a 540 rotações por minuto na tomada de potência do trator, determinada por meio de um tacômetro digital da marca Contact Tchometer, modelo JMDT-2235B, com intervalo de ensaio de 2,5 a 19999 rpm, resolução de $0,1 \mathrm{rpm}(2.5 \sim 999,9 \mathrm{rpm})$ e 1 rpm (acima de $1000 \mathrm{rpm}$ ) e precisão de $0,05 \%+1$ dígito. Para o cálculo do consumo de combustível foram determinados o volume de combustível e o tempo gasto para percorrer uma distância de $20 \mathrm{~m}$, conforme a equação (2).

$$
C h=\frac{3,6 x C}{t}
$$

em que

$\mathrm{Ch}=$ consumo horário de combustível $\left(\mathrm{L} \mathrm{h}^{-1}\right)$;

$\mathrm{C}=$ volume de combustível na unidade experimental, $(\mathrm{mL}) ; \mathrm{e}$

$\mathrm{t}=$ tempo gasto na unidade experimental, $\mathrm{s}$.

A capacidade de trabalho teórica média foi determinada em função da velocidade de deslocamento do conjunto trator-adubadora e largura da faixa trabalhada conforme a equação (3).

$$
C t=\frac{V x L}{10}
$$

em que

$\mathrm{Ct}=$ capacidade de trabalho teórica $\left(\mathrm{ha} \mathrm{h}^{-1}\right)$;

$\mathrm{V}=$ velocidade de deslocamento do conjunto $\left(\mathrm{km} \mathrm{h}^{-1}\right)$; e $\mathrm{L}=$ largura da faixa trabalhada pelo conjunto $(\mathrm{m})$.

O consumo operacional de combustível foi determinado em função do tempo gasto para trabalhar uma área correspondente a um hectare e o consumo horário de combustível conforme a equação (4).

$C o=T x C h$ 
$\mathrm{Co}=$ consumo operacional de combustível $\left(\mathrm{L} \mathrm{ha}^{-1}\right)$; $\mathrm{T}=$ tempo gasto para trabalhar um hectare $\left(\mathrm{h} \mathrm{ha}^{-1}\right) ; \mathrm{e}$ $\mathrm{Ch}=$ consumo horário de combustível $\left(\mathrm{L} \mathrm{h}^{-1}\right)$.

Para a avaliação da incorporação do composto orgânico e índice de velocidade de emergência, foi realizado um experimento utilizando um delineamento em blocos casualizados, com quatro repetições, seguindo um esquema fatorial $2 \times 2$, sendo o primeiro fator constituído pela incorporação do composto orgânico com a adubadora e sem aplicação de composto (testemunha) e o segundo fator pela presença e ausência de palhada.

Cada parcela foi constituída de doze linhas de plantio espaçadas de $0,80 \mathrm{~m}$ e comprimento de dez metros. Nas parcelas com a presença de palhada, foi utilizado o milheto como fonte da mesma, totalizando $4 \mathrm{t} \mathrm{ha}^{-1}$. Após o preparo das parcelas foi realizado a semeadura manual da variedade UFV M100 de milho, preconizando um espaçamento de $0,20 \mathrm{~m}$ entre plantas.

Foram feitas coletas de solo em uma linha de plantio de cada parcela nas camadas de $0,00-0,02$, 0,02-0,04, 0,04-0,06, 0,06-0,08, 0,08-0,10 m de profundidade, utilizando um tubo de metal com diâmetro de $75 \mathrm{~mm}$ e comprimento de $120 \mathrm{~mm}$, recortado em sessões de $20 \mathrm{~mm}$. As amostras foram encaminhadas para o Laboratório de Análise de Solo Viçosa para determinação do teor de carbono orgânico.

O índice de velocidade de emergência (IVE) foi determinado por meio de avaliações diárias de emergência das plântulas de milho, a partir da primeira plântula emergida até a obtenção de número constante, em quatro linhas de quatro metros em cada parcela. O índice de velocidade de emergência de plântulas foi calculado utilizandose a equação (5) (MAGUIRE, 1962).

$$
I V E=\frac{E_{1}}{N_{1}}+\frac{E_{2}}{N_{2}}+\ldots \frac{E_{n}}{N_{n}}
$$

em que

IVE = índice de velocidade de emergência; $\mathrm{E}_{1}, \mathrm{E}_{2}, \mathrm{E}_{\mathrm{n}}=$ número de plantas emergidas, na primeira, segunda, até a última contagem; e
$\mathrm{N}_{1}, \mathrm{~N}_{2}, \mathrm{~N}_{\mathrm{n}}=$ número de dias da semeadura à primeira, segunda, até a última contagem.

Os resultados das avaliações de incorporação de composto orgânico e IVE foram submetidos à análise de variância e as médias, comparadas pelo teste de Tukey, a 5\% de significância.

\section{RESULTADOS DE DISCUSSÃO}

Com base no Quadro 1, observa-se que a potência demandada para tracionar somente o trator utilizado na segunda etapa da avaliação foi de $2,02 \mathrm{~kW}(2,75 \mathrm{cv})$ e a demanda de potência do conjunto trator-adubadora na primeira etapa da avaliação foi de 3,98 kw (5,43 cv). Desta forma, a potência demandada pela adubadora foi de $1,96 \mathrm{~kW}(2,68 \mathrm{cv})$ a uma velocidade de trabalho de $3,3 \mathrm{~km} \mathrm{~h}^{-1}$, portanto, a adubadora poderá ser tracionada e acionada por tratores de baixa potência, até $40 \mathrm{cv}$ segundo ANFAVEA (2011). O valor de demanda de potência para cada linha da adubadora $(0,98 \mathrm{~kW})$ pode ser considerado baixo quando comparado ao valor de $3,57 \mathrm{~kW}$ por linha de plantio, obtido de uma semeadoraadubadora dotada do mecanismo de disco de corte de palhada e facão para deposição de adubo, trabalhando em um solo com textura argilosa, sob sistema de semeadura direta, com uma velocidade de trabalho de $3,4 \mathrm{~km} \mathrm{~h}^{-1}$ (FURLANI et al., 2008).

A força de tração média requerida para tracionar a adubadora foi de $2228,38 \mathrm{~N}$. Com este valor obtêm-se uma força de tração de 1114,19 $\mathrm{N}$ para cada linha da adubadora. Este valor encontra-se abaixo do obtido por Chioderoli et al. (2010), $2200 \mathrm{~N}$ por linha, trabalhando com uma semeadora-adubadora para plantio direto, em uma velocidade de trabalho de $4,5 \mathrm{~km} \mathrm{~h}^{-1}$.

O menor valor de força de tração requerida e demanda de potência para cada linha da adubadora deve-se ao mecanismo de trabalho da adubadora, pois quando as enxadas rotativas são acionadas pela tomada de potência do trator, funcionam como se fossem um eixo auxiliar empurrando o conjunto trator-adubadora, diferentemente da semeadora-adubadora utilizada por Furlani et al. (2008), que somente é tracionada. Além disso, outro fator que pode estar relacionado à menor 
demanda de potência é a diferença entre os pesos da adubadora e da semeadora.

O consumo horário de óleo diesel do conjunto trator-adubadora (Quadro 2) apresentou-se equivalente ao obtido por Reis et al. (2002), que trabalhou com uma semeadora-adubadora Rotacaster, com duas linhas de plantio em diferentes tores de água, em um Argissolo com textura argilosa e obteve o valor médio de $4,14 \mathrm{~L}$ $\mathrm{h}^{-1}$. O consumo horário de óleo diesel por linha de plantio da adubadora adaptada $\left(2,44 \mathrm{~L} \mathrm{~h}^{-1}\right.$ linha $\left.^{-1}\right)$ apresentou-se próximo ao valor de uma semeadoraadubadora de semeadura direta tradicional $(2,50$ $\mathrm{L} \mathrm{h}^{-1}$ linha $^{-1}$ ) composta por disco de corte e facão sulcador, utilizada por Furlani et al. (2008).

Isto ocorre devido ao fato da adubadora necessitar ser acionada pela tomada de potência do trator, o que contribui para maior consumo de óleo diesel. No entanto, o consumo operacional de óleo diesel do conjunto trator-adubadora $\left(18,74 \mathrm{~L} \mathrm{ha}^{-1}\right)$ foi três vezes maior que o consumo operacional do conjunto trator-semeadora-adubadora, de semeadura direta tradicional $\left(6,3 \mathrm{~L} \mathrm{ha}^{-1}\right)$, obtido por Furlani et al. (2008). Este maior consumo operacional deve-se ao fato do conjunto tratoradubadora possuir baixa capacidade de trabalho teórica média $\left(0,26 \mathrm{ha} \mathrm{h}^{-1}\right)$, comparada a do conjunto trator-semeadora-adubadora de semeadura direta tradicional $\left(1,3 \mathrm{ha} \mathrm{h}^{-1}\right)$.

A incorporação do composto orgânico no perfil do solo está representada na Figura 1 pelos teores médios de carbono orgânico até $0,10 \mathrm{~m}$ de profundidade. Observa-se que o maior teor de carbono orgânico $\left(5,20 \mathrm{dag} \mathrm{kg}^{-1}\right)$ foi obtido na profundidade de $0,00-0,02 \mathrm{~m}$, com a incorporação do adubo orgânico na área com a presença de palhada. Para os tratamentos com a aplicação do composto orgânico, nota-se que na medida em que se aprofunda no perfil do solo ocorre uma redução nos teores de carbono orgânico, no entanto, percebe-se que, para tais tratamentos, houve um efeito mais pronunciado nas profundidades de 0,00-0,02 e 0,02-0,04 m, mostrando a eficiência da adubadora em incorporar o composto orgânico no solo, podendo contribuir com a minimização do processo de volatilização do nitrogênio na forma de $\mathrm{NH}_{3}$ e aumentar o contato do mesmo com as raízes das plantas.

Quadro 1. Valores de velocidade, força de tração e potência, da primeira (com adubadora) e da segunda (sem adubadora) etapas da avaliação da demanda de potência de uma adubadora para sistema orgânico de semeadura direta

\begin{tabular}{ccccccc}
\hline \multirow{2}{*}{ Repetição Sem adubadora } & \multicolumn{3}{c}{ Com Adubadora } \\
\cline { 2 - 7 } & $\begin{array}{c}\text { Velocidade } \\
\left(\mathbf{m ~ s}^{-1}\right)\end{array}$ & $\begin{array}{c}\text { Força } \\
\mathbf{( N )}\end{array}$ & $\begin{array}{c}\text { Potência } \\
\mathbf{( k W )}\end{array}$ & $\begin{array}{c}\text { Velocidade } \\
\left(\mathbf{m ~ s}^{-1}\right)\end{array}$ & $\begin{array}{c}\text { Força } \\
\mathbf{( N )}\end{array}$ & $\begin{array}{c}\text { Potência } \\
(\mathbf{k W})\end{array}$ \\
\hline $\mathbf{1}$ & 0,92 & 1774,30 & 1,63 & 0,91 & 4098,06 & 3,73 \\
$\mathbf{2}$ & 0,91 & 2346,65 & 2,14 & 0,90 & 4498,71 & 4,05 \\
$\mathbf{3}$ & 0,93 & 2461,12 & 2,29 & 0,90 & 4670,42 & 4,20 \\
\hline \multirow{2}{*}{ Média } & $0,92 \pm 0,01$ & $2194,02 \pm$ & $2,02 \pm 0,34$ & $0,90 \pm 0,01$ & $4422,40 \pm$ & $3,98 \pm 0,24$ \\
& & 367,96 & & & & \\
\hline
\end{tabular}

Quadro 2. Valores capacidade de trabalho teórica, consumo horário de óleo diesel e consumo operacional de óleo diesel do conjunto trator-adubadora para sistema orgânico de semeadura direta

\begin{tabular}{cccc}
\hline Repetição & $\begin{array}{c}\text { Capacidade de } \\
\text { Trabalho }\left(\mathbf{h a ~ h}^{-1}\right)\end{array}$ & $\begin{array}{c}\text { Consumo horário } \\
\left(\mathbf{L ~ h} \mathbf{~ h}^{-\mathbf{1}}\right)\end{array}$ & $\begin{array}{c}\text { Consumo operacional } \\
\left(\mathbf{L} \mathbf{~ h a}^{-\mathbf{1}}\right)\end{array}$ \\
\hline 1 & 0,26 & 4,96 & 18,73 \\
2 & 0,25 & 4,76 & 18,74 \\
3 & 0,26 & 4,90 & 18,74 \\
\hline Média & $0,26 \pm 0,01$ & $4,87 \pm 0,10$ & $18,74 \pm 0,01$ \\
\hline
\end{tabular}


Para os tratamentos sem a aplicação do composto orgânico (testemunha), com a presença de palhada, observa-se que não houve diferença estatística entre as profundidades, sendo os valores situados próximos a 3,00 dag $\mathrm{kg}^{-1}$ (Figura 1). Já para a testemunha sem a presença de palhada, apenas a profundidade de $8-10 \mathrm{~cm}$ diferiu das demais, apresentando o menor valor $\left(2,50 \mathrm{dag} \mathrm{kg}^{-1}\right)$.

Para os valores de índice de velocidade de emergência (IVE) de plântulas de milho, observa-se no Quadro 3, o efeito significativo da interação da presença e ausência de composto orgânico com a presença e ausência de palhada de milheto, mostrando a importância da presença da cobertura do solo no processo de emergência das plântulas de milho, como evidenciado por Nunes et al. (2003), que testou a influência da cobertura do solo com palhada de sorgo na emergência de plântulas de milho e soja, obtendo um resultado positivo para milho, com incremento de $16 \%$ no IVE, elevando-se a dose de palhada de $0 \mathrm{t}$ $\mathrm{ha}^{-1}$ para $30 \mathrm{t} \mathrm{ha}^{-1}$. Este resultado positivo para presença de palhada sobre o IVE de plântulas de milho pode ser devido à redução do processo de evaporação da água do solo com a presença da palhada, mantendo por mais tempo umidade que favoreça a germinação, elevando o IVE (CRUZ et al., 2007).

A incorporação do composto orgânico no solo favoreceu o IVE das plântulas de milho no solo sem a presença da palhada de milheto. Alguns autores evidenciam que a incorporação de esterco de animais ou outros materiais

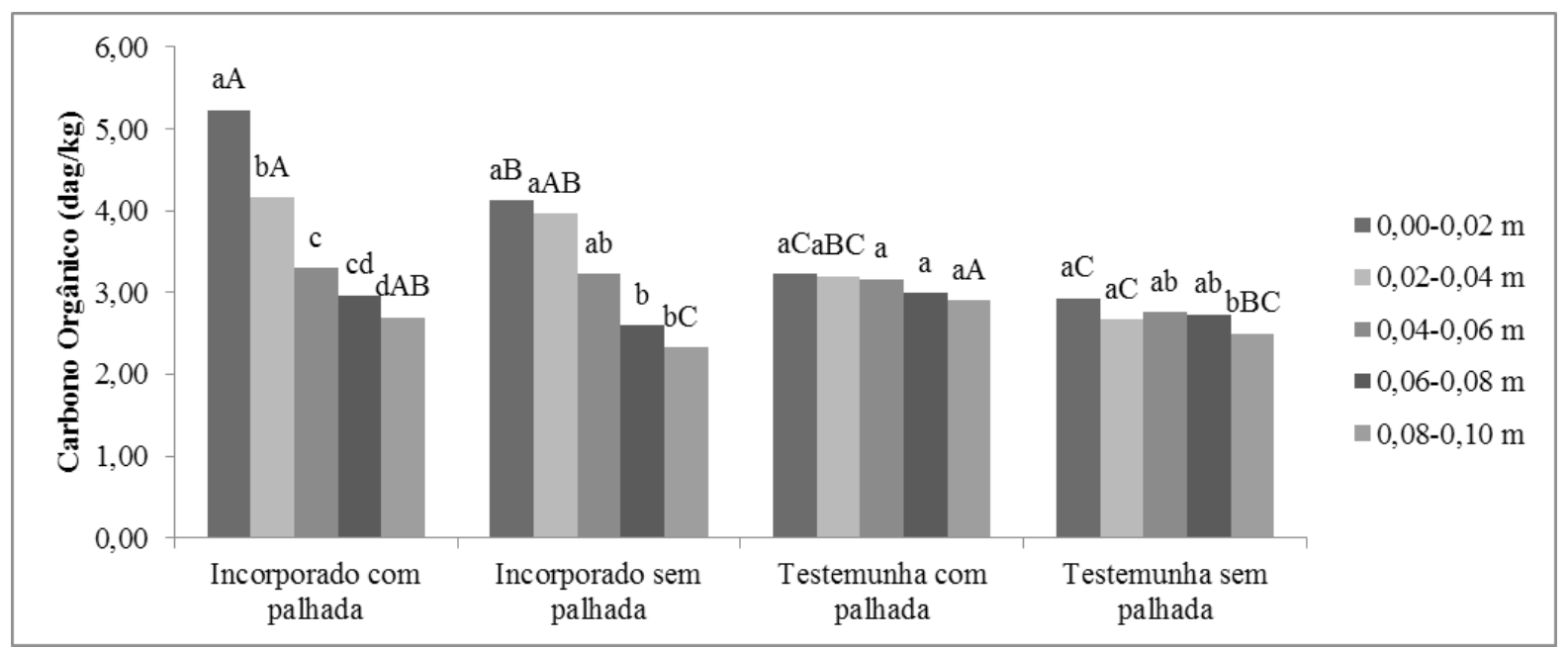

Colunas seguidas pelas mesmas letras minúsculas não apresentaram diferença significativas entre profundidades dentro de cada tratamento. Colunas seguidas pelas mesmas letras maiúsculas não apresentaram diferença significativas entre tratamentos dentro da mesma profundidade.

Figura 1. Valores médios de carbono orgânico em razão da incorporação de composto orgânico no solo e presença e ausência de palhada de milheto.

Quadro 3. Valores médios de Índice de velocidade de emergência (IVE) de plantas de milho. Viçosa - MG, 2012

\begin{tabular}{cccc}
\hline \multirow{2}{*}{ Palhada } & \multicolumn{2}{c}{ Composto orgânico } & \multirow{2}{*}{ MÉDIA } \\
\cline { 2 - 3 } & Incorporado & Sem composto & \\
\hline Com & $6,09 \mathrm{aA}$ & $4,73 \mathrm{aA}$ & 5,41 \\
Sem & $5,60 \mathrm{aA}$ & $3,47 \mathrm{bB}$ & 4,10 \\
\hline MÉDIA & 5,84 & 4,54 \\
\hline CV\% & \multicolumn{4}{|}{} \\
\hline
\end{tabular}

Médias seguidas pelas mesmas letras minúsculas nas linhas e maiúsculas nas colunas não diferiram significativamente pelo teste de Tukey a 5\% de probabilidade. 
orgânicos podem promover efeitos benéficos nas características físicas do solo, tais como: aumento da microporosidade e retenção de água em solos arenosos (HAFEZ, 1974; WEIL \& KROONTJE, 1979). Este efeito positivo pode ser devido à alteração das características físicas do solo no qual foi incorporado o composto orgânico, favorecendo a manutenção do teor de água do solo. Este benefício da presença de composto orgânico sobre o IVE também foi observado em pimenta malagueta por Dias et al. (2008).

\section{CONCLUSÕES}

- A adubadora poderá ser acionada e tracionada por tratores de baixa potência, menor que 40 $\mathrm{cv}$;

- A adubadora apresentou baixa capacidade de trabalho e elevado consumo operacional de óleo diesel;

- O conjunto trator-adubadora foi eficiente em incorporar o adubo orgânico ao solo na camada de $0,0-0,04 \mathrm{~m}$ de profundidade; $\mathrm{e}$

- A incorporação do composto orgânico proporcionou incremento de $36 \%$ no índice de velocidade de emergência de plântulas de milho no solo sem palhada de milheto.

\section{REFERÊNCIAS BIBLIOGRÁFICAS}

\section{ANFAVEA (ASSOCIAÇÃO NACIONAL DOS FABRICANTES DE VEÍCULOS} AUTOMOTORES). Anuário estatístico. 2011. 158p. Disponível em: http://www.anfavea.com. br. Acesso em: 10 abr. 2012.

CHIODEROLI, C.A.; FURLANI, C. E. A.; SILVA, R. P.; GITTI, D. C.; KANEKO, F. H.; ROMAN, R. A. A. Desempenho de semeadora-adubadora em função do preparo de solo e espaçamento da cultura do milho. Pesquisa Agropecuária Tropical, Goiânia, v.40, p.462-467, 2010.

CRUZ, C. C.; ALVARENGA, R. C.; NOVOTNY, E. H.; PEREIRA FILHO, I. A.; SANTANA, D. P.; PEREIRA, F. T. F.; HERNANI, L. C. Sistema plantio direto. Embrapa Milho e Sorgo. Sistema de produção. Versão Eletrônica - 3.ed. Disponível em 25/jan/2007: http://www.cnpms.embrapa.br/ publicacoes/milho/mandireto.htm. Acesso em: 10 de abr. 2012.

DIAS, M. A.; LOPES, J. C.; CORRÊA, N. B.; DIAS, D. C. F. S. Germinação de sementes e desenvolvimento de plantas de pimenta malagueta em função do substrato e da lâmina de água. Revista Brasileira de Sementes, Viçosa, v.30, n.3, p.115-121, 2008.

DIAS, V. O. Desempenho de dois protótipos de semeadoras-adubadoras para plantio direto. 2009. 82 f. Dissertação (Mestrado em Engenharia Agrícola) - Universidade Federal de Santa Maria, Santa Maria - RS, 2009.

EMBRAPA. Centro Nacional de Pesquisa de Solos. Sistema brasileiro de classificação de solos. 2.ed. Rio de Janeiro, 2006. 306p.

FURLANI, C. E. A.; SILVA, R. P.; FILHO, A. C.; CORTEZ, J. W.; GROTTA, D. C. C. Semeadoraadubadora: exigências em função do preparo do solo, da pressão de inflação do pneu e da velocidade. Revista Brasileira de Ciências do Solo, Jaboticabal, v.32, p.345-352, 2008.

HAFEZ, A.A.R. Comparative changes in soilphysical properties induced by mixtures of manures from various domestic animals. Soil Science, Baltimore, v.118, p.53-59, 1974.

JANSEN, H. H.; MCGINN, S. M. Volatile loss of nitrogen during decomposition of legume green manure. Soil Biology and Biochemistry, Oxford, v.23, p.193-297, 1991.

MAGUIRE, J. D. Speed of germination-aid in selection and evaluation for seedling emergence and vigor. Crop Science, Madison, v.2, p.176-177, 1962. MODOLO, A. J.; SILVA, S. L.; SILVEIRA, J. C. M.; MERCANTE, E. Avaliação do desempenho de duas semeadoras-adubadoras de precisão em diferentes velocidades. Engenharia na Agricultura, Viçosa, v.12, p.298-306, 2004. 
NUNES, J. C. S.; ARAUJO, E. F.; SOUZA, C. M.; BERTINI, L. A.; FERREIRA, F. A. Efeito da palhada de sorgo localizada na superfície do solo em características de plantas de soja e milho.

Revista Ceres, Viçosa, v.50, p.115-126, 2003.

REIS, E. F.; VIEIRA, L. B; SOUZA, C. M.; SCHAEFER, C. E. G. R.; FERNANDES, H. C. Avaliação do desempenho de duas semeadoras- adubadoras de plantio direto em diferentes teores de água em um solo argiloso. Engenharia na Agricultura, Viçosa, v.10, p.61-68, 2002.

WEIL, R.R. \& KROONTJE, W. Physical condition of a Davidson Clay Loam after five years of heavy poultry manure applications. Journal of Environmental Quality, Iowa, v.8, p.387-392, 1979. 